\title{
Remoción de bacterias coliformes en un sistema de lodos activados y humedal construido
}

\section{Coliform bacteria removal through a system of activated sludge and constructed wetland}

\author{
Hipólito Muñoz-Nava ${ }^{1 *}$, Jürgen Baumann ${ }^{2}$ \\ ${ }^{1}$ Facultad de Agrobiología. Universidad Autónoma de Tlaxcala. Km. 10.5 autopista Texmelucan-Tlaxcala, CP. 90120, San \\ Felipe Ixtacuixtla, Tlaxcala, México. \\ ${ }^{2}$ Consultor \\ ${ }^{*}$ Autor de correspondencia: hipolito78@hotmail.com
}

Artículo científico recibido: 02 de octubre de 2015, aceptado: 21 de octubre de 2016

RESUMEN. El agua residual municipal contiene grandes cantidades de bacterias coliformes, que pueden ser un riesgo para la salud pública y la contaminación ambiental. El objetivo fue evaluar la remoción de coliformes cotales (CT), Escherichia coli (EC) y demanda química de oxígeno (DQO) del agua residual de un sistema a escala piloto con dos tratamientos: un reactor secuencial por lotes (RSL) de lodos activados y un humedal construido de flujo vertical (HCFV). Las concentraciones promedio de CT, EC y DQO en el efluente fueron $8.03 \times 10^{6}, 4.13 \times 10^{6} \mathrm{NMP}(100 \mathrm{~mL})^{-1}$ y $528 \mathrm{mg} \mathrm{L}^{-1}$, respectivamente. Los Porcentajes de remoción (PR) promedio fueron de $99.84 \%$ (4.52 unidades log), $99.92 \%$ (4.92 unidades log) y $92.78 \%$ para CT, EC y DQO, respectivamente. La remoción, obtenida con un tiempo de residencia aproximado de $11 \mathrm{~h}$, cumple con la norma mexicana para reúso con contacto directo. El análisis de correlación mostró que la DQO es independiente de CT y EC. Las mediciones del efluente y concentraciones de CT y EC en la salida del HCFV muestran que entre las variables hay asociación. Las concentraciones de CT y EC del HCFV con respecto al tiempo estuvieron sesgadas a la izquierda, lo que concuerda con el comportamiento observado para medios porosos. Las comunidades pueden utilizar este sistema para reusar el agua residual tratada en el riego agrícola.

Palabras clave: Demanda química de oxígeno, Escherichia coli, humedal, tasa de efluente

ABSTRACT. Municipal wastewater contains huge amounts of coliforms that represent a risk to public health and can pollute the environment. The goal of this study was to evaluate the removal of total coliforms (TC), Escherichia coli $(E C)$, and chemical oxygen demand (COD) from wastewater by using a pilot system with sequencing batch reactor (SBR) activated sludge and vertical flow constructed wetland (VFCW). Average concentration of TC, EC and COD in the influent were $8.03 \times 10^{6}, 4.13 \times 10^{6} \mathrm{NMP}(100 \mathrm{~mL})^{-1}$, and $528 \mathrm{mg} \mathrm{L}{ }^{-1}$, respectively; the average removal percent (RP) were $99.84 \%$ (4.52 log units), $99.92 \%$ (4.92 log units), and $92.78 \%$ for TC, EC, and COD, respectively. This removal, obtained with $11 \mathrm{~h}$ of time residence, meets with Mexican requirements for water reuse. Correlation analysis showed that the COD was not correlated with TC and EC. Measures flux effluent, and TC and EC concentrations from the outflow of VFCW show that these variables are related. Plots of TC and EC concentrations from VFCW versus time were skewed to the left; this result is similar as observed in porous medium. Therefore, communities can use this system to reuse treated wastewater in agriculture irrigation.

Key words: Chemical oxygen demand, Escherichia coli, effluent flux, wetland

\section{INTRODUCCIÓN}

Las aguas residuales municipales y domésticas tienen grandes cantidades de bacterias coliformes y patógenos que se deben remover para evitar riesgos a la salud y la contaminación ambiental (Tchobanoglous et al. 2003). La eficiencia de una planta de tratamiento de aguas residuales depende 
de la cantidad y calidad del agua residual, de las condiciones y del tipo de recolección, de la fuente, uso de equipamiento técnico, del clima y de muchos otros factores (Vítěz et al. 2012). En las plantas depuradoras se remueven contaminantes en cada fase de tratamiento. Por ejemplo, un porcentaje importante de materia orgánica se remueve en el tratamiento primario y secundario. Sin embargo, en el caso de las bacterias coliformes es necesario aplicar un tratamiento terciario para su remoción (Hammer y Hammer 2001). En esta última fase se combinan tratamientos para alcanzar niveles de remoción de microorganismos que cumplan con los límites máximos establecidos en la normatividad mexicana (Jiménez 2010). Existen varios Métodos para remover o inactivar los coliformes, como la radiación ultravioleta (Beltrán y Jiménez 2008, Amin et al. 2010); combinación de lodos activados con bioreactor de membrana (Arévalo et al. 2009); sistema biológico y desinfección a base de cloro-gas (Bolzonella et al. 2010); sistema de lodos activados combinado con reactor anaerobio de flujo ascendente (Kumar y Patel 2011); materiales filtrantes (Mwabi et al. 2012); entre otros.

En relación con los sistemas filtrantes, como los humedales construidos, se ha visto que tienen buena capacidad de remoción de bacterias coliformes. Los humedales construidos su pueden dividir, con base en el flujo de agua, en superficiales, subsuperficiales e híbridos o combinados; los de flujo subsuperficial se subdividen en horizontales y verticales (Vymazal 2011). Al respecto Hagendorf et al (2005) señala que con un buen pretratamiento y humedal construido de flujo vertical, se logra reducir la concentración de coliformes fecales en $10^{4}$ bacterias por $100 \mathrm{~mL}$. Mientras que Lara y Vera (2005) reportan remociones del $80 \%$ con un humedal construido de flujo subsuperficial. En tanto que Herrera-Melián et al. (2010) con humedales construidos híbridos de flujo vertical y flujo subsuperficial horizontal tuvieron remociones mayores del $78 \%$ de contaminantes y del $99.5 \%$ de coliformes fecales. También se ha reportado que el humedal construido de flujo vertical es confiable en la operación y proporciona una mejor remoción de bacterias que el humedal de flujo horizontal (Windward et al. 2008). Por lo que los humedales naturales y construidos pueden remplazar el tratamiento terciario (Carey y Migliaccio 2009). Por lo anterior el objetivo del trabajo fue evaluar la eficiencia de remoción de coliformes totales (CT), Eschercihia coli (EC) y la demanda química de oxígeno (DQO) del agua residual cruda de una casa habitación.

\section{MATERIALES Y MÉTODOS}

Se utilizó un sistema de tratamiento de agua residual doméstica (STARD), que se instaló en una casa habitación en San Matías Tepetomatitlán, Tlaxcala, México. Se contruyó con un reactor secuencial por lotes (RSL) de lodos activados y un humedal construido de flujo vertical (HCFV) (Figura 1). El suministro de oxígeno en el RSL se realizó con un aireador superficial modelo $A Q U A m a x{ }^{\circledR}$ Classic $Z$ fabricado por ATB. En cada ciclo de operación el RSL trató $300 \mathrm{~L}$ de agua residual por $8 \mathrm{~h}$. El agua residual tratada (ART1) se bombeó al HCFV. El efluente del HCFV (ART2), se almacenó en un depósito para su posterior reúso; el área del HCFV fue de $7.29 \mathrm{~m}^{2}$ y de $0.8 \mathrm{~m}$ de altura. Para la construcción del HCFV se excavó una fosa y se colocó una lámina de polipropileno de $0.6 \mathrm{~mm}$ como impermeabilizante. El medio filtrante fue una capa de arena de $70 \mathrm{~cm}$, la cual se colocó entre dos capas de grava de $10 \mathrm{~cm}$, una en el fondo y la otra en la parte superior. La arena se cribó con un tamiz comercial calibre 8X8, para luego lavar con agua de la llave para eliminar la arcilla adherida. La granulometría de la arena fue $d 9=0.177, \mathrm{~d} 50=0.59$, $\mathrm{d} 85=1$ y d100 $=3.15$. Su conductividad hidráulica saturada fue de $0.49 \mathrm{~cm} \mathrm{~s}^{-1}$, que corresponde a una arena bien graduada (Fetter 2001). En el HCFV se sembró carrizo (Arundo donax) a densidad de cinco plántulas por $\mathrm{m}^{2}$. El humedal estuvo a la intemperie bajo condiciones climáticas de la localidad. Para la aplicación del ART1 al HCFV, se le colocó en la parte superior una red de tubos de PVC.

Para cuantificar las remociones de CT y EC, se tomaron muestras del agua residual cruda del tanque amortiguador (ARC), del ART1 y ART2. 

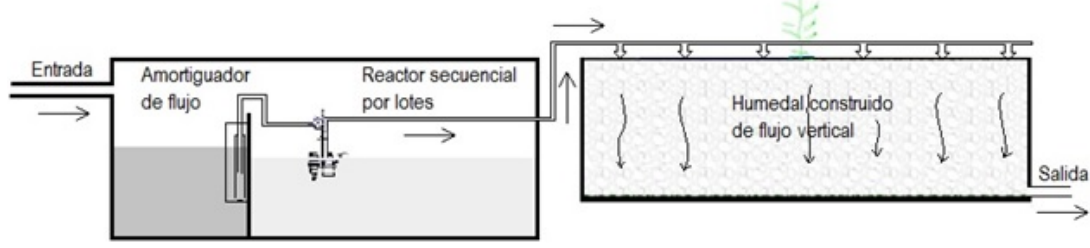

Figura 1. Sistema de tratamiento de agua residual doméstica (Aquatec México).

Las muestras de agua se recolectaron en frascos de $100 \mathrm{~mL}$ que se guardaron en una hielera para trasladarse al laboratorio, para cuantificar el número más probable (NMP). En total se realizaron 11 muestreos, uno en diciembre de 2010; en 2011 se realizaron muestreos en marzo, abril y junio; en enero y septiembre se realizaron dos y en febrero tres. Los muestreos se utilizaron para cuantificar la remoción de la demanda química de oxígeno (DQO). El porcentaje de remoción (PR) de CT, EC y de DQO, en el RSL y en el HCFV se calculó con la fórmula:

$$
P R=\frac{\text { Entrada }- \text { Salida }}{\text { Entrada }} * 100
$$

Para conocer el comportamiento de la tasa del efluente y de las concentraciones de CT y EC con respecto al tiempo en la salida del HCFV, se midió el volumen del efluente cada cinco minutos y se realizaron muestreos de agua en intervalos regulares, durante la duración de la descarga. Las muestras de agua se trataron de la misma manera que se hizo en la cuantificación del PR. Para la tasa del efluente con respecto al tiempo, se realizaron ocho sesiones de medición y para la tasa del efluente junto con las concentraciones de CT y EC se realizaron cuatro sesiones. La relación entre la tasa del efluente y las concentraciones de CT y EC se cuantificó por el coeficiente de correlación, para luego graficar las variables con respecto al tiempo.

La cuantificación del NMP de CT y EC en $100 \mathrm{~mL}$ de muestra se realizó empleando el método desarrollado por IDEXX Laboratories (Westbrook $\mathrm{ME}$ ) que usa la técnica DST ${ }^{\circledR}$ (Defined Sustrate
Technology). Esta técnica emplea dos sustratos enzimáticos, uno es el cromógeno que reacciona con la enzima que se encuentra en CT (galactosidasa) y el otro es un fluorogen que reacciona con una enzima que se encuentra en EC (glucuronidasa). La DQO se cuantificó empleando el método de digestión con dicromato de potasio (O'Dell 1993), utilizando un termoreactor HANNA HI 938800 y la cuantificación con un fotómetro multiparámetrico HANNA HI 83099. Los datos se analizaron con estadística descriptiva, desviación estándar y coeficiente de variación. También se calcularon correlaciones

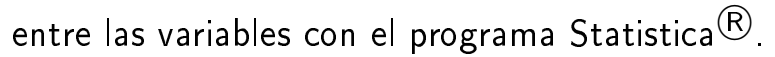

\section{RESULTADOS}

De las 69 muestras de agua obtenidas en el STARD se obtuvieron 52 datos útiles, debido a CT y EC de 17 muestras tuvo valores fuera del límite de detección del conteo (Tabla 1). Los datos muestran que los valores de los parámetros tuvieron una tendencia a disminuir de la entrada a la salida del sistema. El coeficiente de variación (CV) de la DQO fue menor en el RSL, mientras que CT y EC incrementaron de la entrada a la salida. Los datos de DQO en el RSL presentaron los menores CV y los CT en HCFV tuvieron los mayores valores de CV.

Los coeficientes de correlación se presentan en la Tabla 2. Las correlaciones entre la DQO y CT, DQO y EC fueron no significativas en los dos tratamientos. Mientras que el coeficiente de correlación entre CT y EC fue significativo a un $\alpha=0.05$, en las tres fases del sistema de tratamiento. Las pendientes de las ecuaciones de regresión entre 
Tabla 1. Parámetros medidos en el agua del sistema de tratamiento.

\begin{tabular}{|c|c|c|c|c|c|c|c|c|}
\hline Muestreo & Parámetro & $\mathrm{N}$ & Promedio & Media Geométrica & Mínimo & Máximo & $\mathrm{DE}$ & CV \\
\hline \multirow[t]{3}{*}{ ARC } & DQO* & 10 & 528.0 & & 164.0 & 1497.0 & 375.0 & 70.9 \\
\hline & CT** & 9 & $8.03 \times 10^{6}$ & $3.318 \times 10^{6}$ & $1.31 \times 10^{5}$ & $3.65 \times 10^{7}$ & $1.11 \times 10^{7}$ & 139.1 \\
\hline & $\mathrm{EC} * *$ & 9 & $4.13 \times 10^{6}$ & $1.447 \times 10^{6}$ & $6.10 \times 10^{4}$ & $1.84 \times 10^{7}$ & $5.98 \times 10^{6}$ & 144.7 \\
\hline \multirow[t]{3}{*}{ ART1 } & DQO* & 10 & 85.6 & - & 40.0 & 181.0 & 47.1 & 55.0 \\
\hline & $\mathrm{CT} * *$ & 11 & $3.75 \times 10^{4}$ & 8355.0 & $1.90 \times 10^{3}$ & $1.55 \times 10^{5}$ & $5.91 \times 10^{4}$ & 157.3 \\
\hline & $\mathrm{EC} * *$ & 10 & $2.11 \times 10^{4}$ & - & 0.0 & $7.67 \times 10^{4}$ & $3.15 \times 10^{4}$ & 149.7 \\
\hline \multirow[t]{3}{*}{ ART2 } & DQO* & 9 & 25.7 & - & 3.0 & 52.0 & 18.19 & 70.8 \\
\hline & $\mathrm{CT}^{* *}$ & 11 & $3.77 \times 10^{3}$ & 199.0 & $2.00 \times 10^{0}$ & $2.59 \times 10^{4}$ & $8.12 \times 10^{3}$ & 215.3 \\
\hline & $\mathrm{EC} * *$ & 9 & $1.44 \times 10^{3}$ & $\longrightarrow$ & 0.0 & $8.21 \times 10^{3}$ & $2.97 \times 10^{3}$ & 205.4 \\
\hline
\end{tabular}

Tabla 2. Correlaciones de las variables en las fases del sistema de tratamiento de agua residual doméstica.

\begin{tabular}{|c|c|c|c|c|}
\hline Proceso & Parámetro & $\mathrm{N}$ & $\mathrm{R}$ & Ecuación de regresión \\
\hline Tanque & DQO:CT & 7 & 0.070987 & \\
\hline \multirow[t]{2}{*}{ Amortiguador } & DQO:EC & 7 & 0.355485 & \\
\hline & CT:EC & 9 & 0.854167 & $\mathrm{EC}=0.5182 * \mathrm{CT}-27594$ \\
\hline \multirow[t]{3}{*}{ RSL } & DQO:CT & 8 & 0.223239 & \\
\hline & DQO:EC & 7 & 0.314602 & \\
\hline & CT:EC & 9 & 0.964193 & $\mathrm{EC}=0.5034 * \mathrm{CT}+377.2$ \\
\hline \multirow[t]{3}{*}{ HCFV } & DQO:CT & 8 & -0.463095 & \\
\hline & DQO:EC & 6 & -0.478019 & \\
\hline & CT:EC & 8 & 0.993515 & $\mathrm{EC}=0.3298 * \mathrm{CT}-1.9521$ \\
\hline
\end{tabular}

CT y EC fueron positivas del orden de 0.5 en el influente y en el RSL, y disminuyó a 0.3 en el HCFV.

Los porcentajes de remoción (PR) de los procesos RSL, HCFV y total del sistema se presentan en la Tabla 3. Los PR promedio del sistema fueron del $92.87 \%, 99.84 \%$ (4.52 unidades $\log _{10}$ ) y $99.92 \%$ (4.92 unidades $\log _{10}$ ) para DQO, CT y $E C$, respectivamente. Los promedios y mínimos del PR para DQO, CT y EC fueron mayores en el RSL que en el HCFV; los máximos del PR para CT y EC fueron mayores en el HCFV. La remoción tuvo mayor coeficiente de variación y desviación estándar en el proceso del HCFV que en el del RSL, mientras que la DQO tuvo mayor variación que el CT y EC. Las remociones en el RSL fueron de $79.72,98.62$ (2.51 unidades $\log _{10}$ ) y $99.03 \%(2.81$ unidades $\log _{10}$ ) para los parámetros de DQO, CT y EC, respectivamente. En el HCFV los porcentajes de remoción fueron del 75.59, 95.42 (1.92 unidades $\log _{10}$ ) y $97.15 \%$ (2.34 unidades $\log _{10}$ ), de los tres parámetros evaluados, respectivamente. La con- tribución del HCFV en la remoción total del sistema fue del $14.53,1.22$ y $0.88 \%$ para DQO, CT y EC, respectivamente.

Los datos de las mediciones del volumen del efluente en el HCFV con respecto al tiempo, se encuentran en la Figura 2. El tiempo en que se registró flujo en la salida del HCFV por la aplicación de ART1 fue de 10 min después de cada inicio del riego. El flujo aumentó hasta alcanzar su máximo valor a los $50 \mathrm{~min}$ y después descendió de forma paulatina. Las curvas de los flujos están sesgadas a la izquierda; el mayor flujo fue de $106.8 \mathrm{~mL} \mathrm{\textrm {min } ^ { - 1 }}$ y el menor de $9.46 \mathrm{~mL} \mathrm{~min}^{-1}$, los cuales se registraron en los muestreos del 13 de julio y 8 de agosto, respectivamente. El flujo promedio fue de $42.0 \mathrm{~mL}$ $\min ^{-1}$ con desviación estándar de $33.3 \mathrm{~mL} \mathrm{~min}{ }^{-1}$.

Las variaciones de las concentraciones de $C T$, EC y la tasa del efluente del HCFV con respecto al tiempo de medición se encuentran en la Figura 3. Se observa que las concentraciones de CT y EC tuvieron el mismo comportamiento que la tasa del 


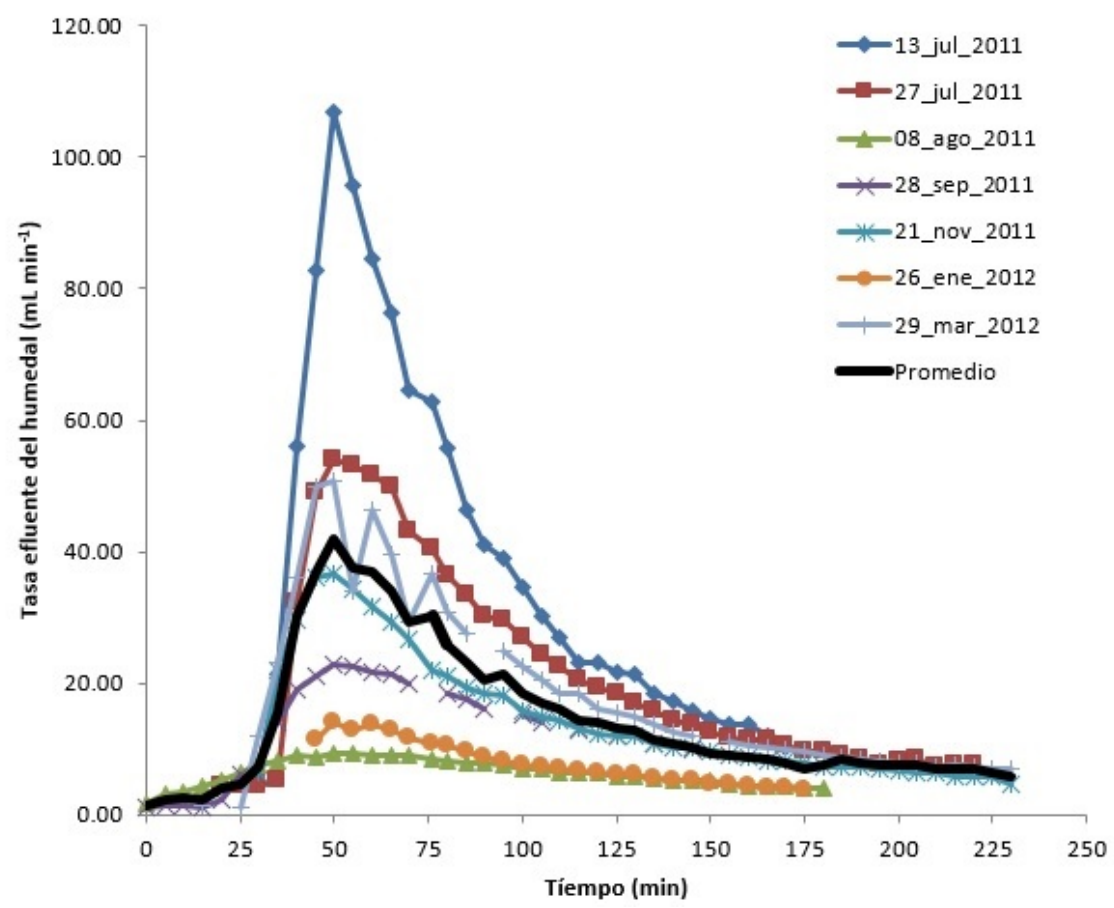

Figura 2. Variación del flujo en el efluente del humedal construido durante la medición.

Tabla 3. Estadística Básica del Porcentaje de Remoción (\%) de la DQO, CT y EC en el RSL, HCFV y Total del sistema de tratamiento de agua residual doméstica.

\begin{tabular}{llcrlllr}
\hline Parámetro & Proceso & $\mathrm{N}$ & Promedio & Mínimo & Máximo & DE & CV \\
\hline DQO & RSL & 10 & 79.72 & 43.29 & 90.61 & 14.59 & 18.30 \\
& HCFV & 9 & 75.59 & 44.09 & 100.0 & 17.85 & 23.61 \\
& HCFV* & 8 & 14.53 & 8.87 & 25.0 & 5.93 & 40.79 \\
& Total & 9 & 92.78 & 68.29 & 100.0 & 10.01 & 10.79 \\
CT & RSL & 9 & $98.62(2.51)$ & $94.51(1.26)$ & $99.99(4.28)$ & $1.76(1.06)$ & 1.78 \\
& HCFV & 10 & $95.42(1.92)$ & $76.86(0.64)$ & $100.0(3.30)$ & $7.07(0.85)$ & 7.41 \\
& HCFV* & 9 & 1.22 & 0.00 & 4.22 & 1.39 & 114.09 \\
EC & Total & 9 & $99.84(4.52)$ & $98.73(1.90)$ & $100.0(6.62)$ & $0.42(1.49)$ & 0.42 \\
& RSL & 9 & $99.03(2.81)$ & $96.22(1.42)$ & $100.0(6.27)$ & $1.19(1.56)$ & 1.20 \\
& HCFV & 9 & $97.15(2.34)$ & $82.40(0.75)$ & $100.0(3.30)$ & $5.86(0.89)$ & 6.04 \\
& HCFV* & 9 & 0.88 & 0.00 & 3.11 & 1.00 & 113.00 \\
& Total & 9 & $99.92(4.92)$ & $99.33(2.18)$ & $100.0(6.49)$ & $0.22(1.49)$ & 0.22 \\
\hline
\end{tabular}

$\overline{\mathrm{RSL}}=$ reactor secuencial por lotes, HCFV = humedal construido de flujo vertical, DQO = demanda química de oxígeno, $\mathrm{CT}=$ coliformes totales, $\mathrm{EC}=$ Escherichia coli, $\mathrm{DE}=$ desviación estándar, $\mathrm{CV}=$ coeficiente de variación, $\mathrm{HCFV}^{*}=$ Contribución al porcentaje total de remoción. Números entre paréntesis indican la remoción de bacterias en unidades logarítmicas base 10 .

efluente del HCFV. Las concentraciones de microorganismos aumentaron de forma proporcional con la tasa del efluente. Los picos de CT estuvieron entre 31062 NMP $(100 \mathrm{~mL})^{-1}$ el 21 de noviembre y 1 976 NMP $(100 \mathrm{~mL})^{-1}$ el 28 de septiembre. Para EC los picos estuvieron entre 24066 NMP (100 $\mathrm{mL})^{-1}$ y 1226 NMP $(100 \mathrm{~mL})^{-1}$ en las mismas fechas de CT. El menor promedio de CT y EC se obtuvo el 28 de septiembre y el mayor promedio el 21 de noviembre. La menor variación de las concentraciones de estos microorganismos se obtuvo en el muestro del 28 de septiembre. 

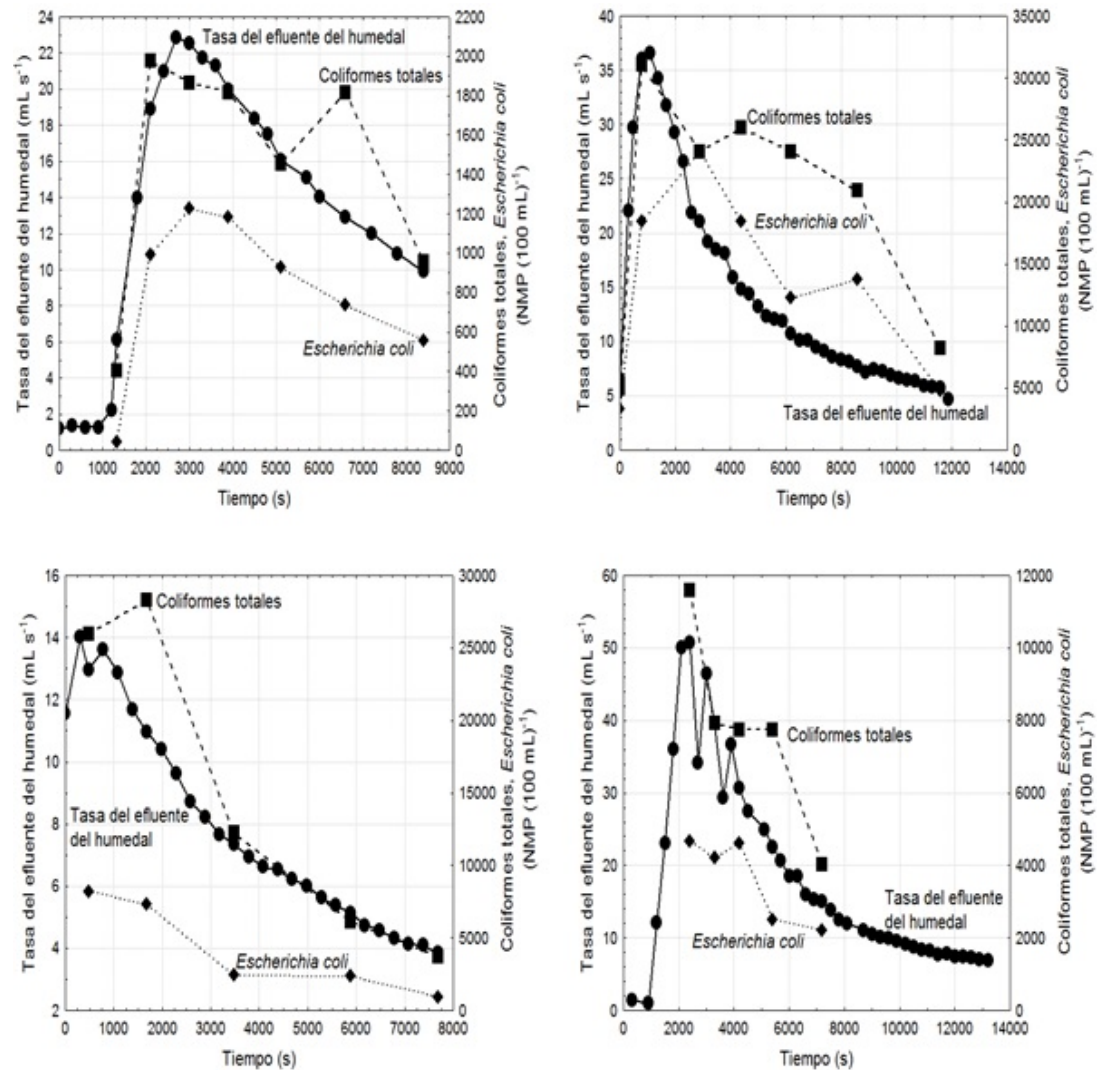

Figura 3. Concentraciones de CT, EC y tasa del efluente del HCFV con respecto al tiempo.

\section{DISCUSIÓN}

EI ARC generado tuvo concentraciones en NMP $(100 \mathrm{~mL})$ de CT entre $10^{5}$ y $10^{7}$, concentraciones menores en dos unidades log al compararlos con los valores de $10^{7}$ y $10^{9}$ reportados por Tchobanoglous et al. (2003), para EC la media geométrica fue mayor al reportado para agua residual cruda y para efluentes de tanques amortiguadores (Lowe et al. 2009). Las concentraciones de $\mathrm{DQO}$ en el ARC se encontraron entre 164 y 1 $497 \mathrm{mg} \mathrm{L}^{-1}$, intervalo que se encuentra fuera de los límites de la tabla guía de Tchobanoglous et al. (2003). Sin embargo, el promedio de $528 \mathrm{mg} \mathrm{L}^{-1}$ de DQO fue mayor que el valor de concentración media de la tabla, y mayor al valor de $444 \mathrm{mg} \mathrm{L}^{-1}$ de DQO reportado por Lowe et al (2009) para efluentes de tanques sépticos. Los valores obtenidos de DQO posiblemente se deban a que el STARD se instaló cerca de la casa y por lo tanto, el efluente no se diluyó por la entrada de agua con menor concentración de contaminantes como puede ocurrir en la red de drenaje.

Los bajos valores de los coeficientes de correlación entre el NMP de CT, EC y DQO, indican que no hubo asociación entre variables microbiológicas y químicas, en las tres fases de la STARD. Sin embargo, los coeficientes de correlación entre estas variables aumentaron en cada proceso de tratamiento. Lo que indica que el agua residual generada, contiene compuestos químicamente oxidables que no tienen relación con los microorganismos coliformes. Al respecto Olutiola et al. (2010) y Kumar-Tyagi et al. (2008), en plantas de tratamiento, y Kagalou et al. (2002) en cuerpos de agua, encontraron relación entre la demanda bio- 


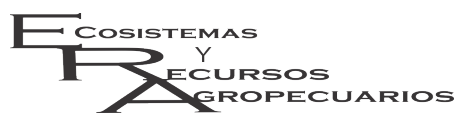

química de oxígeno y las bacterias coliformes. Sin embargo, Hammer y Hammer (2001), señalan que existe relación no uniforme entre la DQO y la DBO, y entre la DQO y las bacterias coliformes.

El porcentaje promedio de remoción de DQO fue del $93 \%$ en la STARD de lodos activados y HCFV, es comparable con la eficiencia reportada en plantas de lodos activados de flujo continuo (Oliveira y Von Sperling 2011). Altos valores de remoción de DQO han sido obtenidos en experimentos controlados en laboratorio, como los realizados por Magnaye et al. (2009) y Syamimi-Musa y AzlinaAhmad (2010). En la mayoría de los casos las eficiencias de remoción en plantas de tratamiento, son inferiores al $90 \%$ (Oliveira y Von Sperling 2011, Suhendrayatna et al. 2012, Panigatti et al. 2013).

Las muestras del efluente del proceso de RSL tuvieron concentraciones de DQO promedio de 25.7 $\mathrm{mg} \mathrm{L}^{-1}$, por lo que cumplen con el límite de DBO establecido (SEMARNAP 2003a), ya que la relación DBO/DQO para aguas residuales tratadas es de 0.1 a 0.3 (Tchobanoglous et al. 2003). Sin embargo, la remoción de CT y EC por el RSL no es la adecuada para reúso de agua residual tratada en riego agrícola (SEMARNAP 2003a) y en servicios al público con contacto directo, indirecto u ocasional (SEMARNAP 2003b). Pero con la implementación del HCFV después de los lodos activados, las concentraciones de DQO y bacterias fueron menores.

Las curvas de la tasa del efluente del HCFV con respecto al tiempo (Figura 2) tuvieron tendencias típicas de las obtenidas en la aplicación de trazadores en forma de pulsos a medios porosos. Este tipo de curvas de campana asimétricas sesgadas a la izquierda han sido obtenidas en experimentos de inyección de trazadores en humedales de flujo horizontal (Kadlec y Wallace 2009, Zahraeifard y Deng 2011), y en humedales de flujo vertical con bombeo continuo (Herrera-Melían et al. 2010). Al respecto Toscano et al. (2009), Langergraber $(2007,2008)$ en humedales construidos de flujo vertical y Dittmer et al. (2005) en columnas, reportan el mismo tipo de curvas cuando aplican carga hidráulica intermitente. Las variaciones de las tasas del efluente (Figura 2), se deben a que el pro-
Muñoz-Nava y Baumann et al. Sistema para remoción de coliformes Ecosist. Recur. Agropec. 4(11):287-297,2017

ceso de infiltración es extremadamente sensible a la variación de las condiciones ambientales y a la combinación de condiciones como la carga hidráulica, la forma de drenar en el fondo del sistema y la carga de presión en la superficie.

La Figura 3 muestra las tasas del efluente y las concentraciones de CT y EC en la salida del HCFV con respecto al tiempo. Se observa una relación entre la tasa del efluente y las concentraciones de CT y EC. Esta relación medida con el coeficiente de correlación, tiene valores entre 0.747 y 0.965 para la tasa del efluente y CT, y entre 0.688 y 0.973 para la tasa del efluente y EC. La forma de las curvas de CT y EC, se encuentran sesgadas a la izquierda, similares a las obtenidas en pruebas al inyectar trazadores en pulsos a medios porosos (Kadlec y Wallace 2009, Zahraeifard y Deng 2011). Generalmente los trazadores no son retenidos en la superficie del medio poroso, debido a que las cargas eléctricas de sus superficies son iguales. En el caso particular de las bacterias gram-negativas como EC, se sabe que la carga neta superficial de su membrana en sistemas naturales acuáticos es negativa (Foppen y Schijven 2006). La cual se origina de las moléculas superficiales expuestas, principalmente de lipopolisacáridos (Coughlin et al. 1983), y de cantidades traza de sustancias poliméricas extracelulares en la parte externa de la membrana celular (Walker et al. 2005). La carga eléctrica negativa de la membrana de las bacterias explica el comportamiento de la concentración de CT y EC, en el efluente del HCFV, la cual es semejante al de los trazadores. Los resultados muestran que existe retención de estas bacterias en la superficie del medio poroso. Estas discrepancias se atribuyen a las heterogeneidades de carga eléctrica en la superficie en los granos de arena y por factores como las fuerzas fisicoquímicas, involucrados en la retención de bacterias y coloides en medios porosos (Torkzaban et al. 2008). Entre los factores se encuentra que la membrana de Escherichia coli es negativa, como la de Campilobacter jejuni (Bolster et al. 2006); a mayor carga hidráulica disminuye la retención (Guber et al. 2005); cuando el grano de arena es más fino hay mayor filtración de las 
bacterias (Entry y Farmer 2001); la predación por protozoarios y la lisis son los principales mecanismos de remoción (Wand et al. 2007) y el mayor contenido de materia orgánica, disminuye la fijación de bacterias (Landa-Cansigno et al. 2013). Por lo que la retención de CT y EC en el humedal construido es un proceso en el que interactúan múltiples factores, que hacen que sea un proceso complejo.

\section{CONCLUSIONES}

Las concentraciones de DQO y EC en el agua residual cruda son mayores a lo reportado, pero las concentraciones de CT son menores. El coeficiente de correlación indica que no hubo relación entre los valores de DQO con los de CT y EC. El sistema de tratamiento empleado produjo una remoción promedio de 4.52 y 4.92 unidades log para CT y EC, respectivamente, y de $93 \%$ para DQO. Con la combinación de los procesos de lodos activados y el humedal construido, se tuvo agua residual tratada que cumple con los límites establecidos en la normatividad mexicana para reúso con contacto directo. La variación de las curvas de las tasas del efluente de la salida del humedal es un indicio de que el proceso de filtración es sensible a las condiciones ambientales y del humedal. Se observó relación entre la tasa del efluente del humedal y las concentraciones de CT y EC, por lo que la retención de bacterias por el medio filtrante, se debe a la combinación de diversos factores.

\section{AGRADECIMIENTOS}

A la empresa Aquatec México S. de R.L. de C.V. por las facilidades del sistema de tratamiento, el laboratorio y personal, para la realización del trabajo.

\section{LITERATURA CITADA}

Amin MM, Movahhedian AH, Ghasemian M, Hashemi H, Farrokhzadeh H, Bina B (2010) Pilot-scale studies of combined clarification, filtration, and ultraviolet radiation systems for disinfection of secundary municipal wastewater effluent. Desalinization 260: 70-78.

Arévalo J, Garralón G, Plaza F, Moreno B, Pérez J, Ángel GM (2009) Wastewater reuse after treatment by tertiaryultrafiltration and a membrane bioreactor (MBR): A comparative study. Desalinization 243: $32-41$.

Beltrán NA, Jiménez BE (2008) Faecal coliforms, faecal enterococci, Salmonella typhi and Acanthamoeba spp. UV inactivation in three different biological effluents. Water SA 34: 261-269.

Bolster CH, Walker SL, Cook KL (2006) Comparison of Escherichia coli and Campylobacter jejuni transport in saturated porous media. Journal of Environmental Quality 35: 1018-1025.

Bolzonella D, Fatone F, Di Fabio S, Cecchi F (2010) Application of membrane biorector technology for wastewater treatment and reuse in the Mediterranean Region: focusing on removal efficiency of nonconventional pollutants. Journal Environmental Management 91: 2424-2431.

Carey RO, Migliaccio KW (2009) Contribution of wastewater treatment plant effluents to nutrient dynamics in aquatic systems: a review. Environment Management 44: 205-217.

Coughlin RT, Tonsager S, McGroarty EJ (1983) Quantitation of metal cations bound to membranes and extracted lipopolysaccharide of Escherichia coli. Biochemistry 22: 2002-2007.

Dittmer U, Meyer D, Langergraber G (2005) Simulation of a subsurface vertical flow constructed wetland for CSO treatment. Water Science and Technology 51: 225-232.

Entry JA, Farmer N (2001) Movement of Coliform bacteria and nutrients in ground water flowing through basalt and sand aquifers. Journal of Environmental Quality 30: 1533-1539. 
Fetter CW (2001) Applied Hydrogeology. 4th Edition. Prentice-Hall Inc. New Jersey, USA. 598p.

Foppen JA, Schijven JF (2006) Evaluation of data from the literature on the transport and survival of Escherichia coli and thermotolerant coliforms in aquifers under saturated conditions. Water Resource 40: 401-426.

Guber AK, Shelton DR, Pachepsky YA (2005) Transport and retention of manure-borne coliforms in soil. Vadose Zone Journal 4: 828-837.

Hagendorf U, Diehl K, Feuerpfeil I, Hummel A, Lopez-Pila J, Szewzyk R (2005) Microbial investigations for sanitary assessment of wastewater treated in constructed wetland. Water Research 39: 4849-4858.

Hammer MJ, Hammer Jr. MJ (2001) Water and wastewater technology. Prentice-Hall Inc. New Jersey, USA. 536p.

Herrera-Melián JA, Martín-Rodríguez AJ, Araña J, González-Díaz O, González-Henríquez JJ (2010) Hybrid constructed wetlands for wastewater treatment and reuse in the Canary Islands. Ecological Engineering 36: 891-899.

Jiménez CBE (2010) Soluciones tecnológicas a la contaminación del agua. En: Aguilar IA (coord.) Calidad del agua, un enfoque multidisciplinario. UNAM, México, DF. pp: 177-198.

Kadlec RH, Wallace S D (2009) Treatment Wetlands. 2nd Edition. CRC Press. Florida, USA. 1000p.

Kagalou I, Tsimarakis G, Bezirtzoglou E (2002) Inter-relationships between bacteriological and chemical variations in Lake Pamvotis-Greece. Microbial Ecology in Heatlh and Disease 14: 37-41.

Kumar MA, Patel K (2011) Coliforms removal in two UASB + ASP based systems". International Biodeterioration and Biodegradation 65: 23-28.

Kumar-Tyagi V, Kazmi AA, Chopra AK (2008) Removal of fecal indicators and pathogens in a waste stabilization pond system treating municipal wastewater in India. Water Environment Research 80: 2111-2117.

Walker SL, Redman JA, Elimelech M (2005) Influence of growth phase on bacterial deposition: interaction mechanisms in packed-bed column and radial stagnation point flow systems. Environment Science Technology 39: 6405-6411.

Landa-Cansigno O, Durán-Álvarez JC, Jiménez-Cisneros (2013) Retention of Escherichia coli, Giardia lamblia cysts and Ascaris lumbricoides eggs in agricultural soils irrigated by untretaed wastewater. Journal of Enviromental Management 128: 22-29.

Langergraber G (2007) Simulation of the treatment performance of outdoor subsurface flow constructed wetlands in temperate climates. Science of the Total Enviroment 380: 210-219.

Langergraber G (2008) Modeling of processes in subsurface flow constructed wetlands: a review. Vadose Zone Journal 7: 830-842.

Lara BJA, Vera PIL (2005) Implantación y evolución de un humedal artificial de flujo subsuperficial en Cogua, Cundinamarca, Colombia. Ingeniería y Universidad 39: 47-63.

Lowe KS, Tucholke MB, Tomaras JMB, Conn K, Hoppe C, Drewes JE, et al. (2009) Influent constituent characteristics of the modern waste stream from single sources. Water Environment Research FoundationIWA Publishing. Virginia, USA. http://www.ndwrcdp.org/documents/04-dec-1/04dec01web.pdf. Fecha de consulta 21 de septiembre de 2015.

Magnaye FA, Gaspillo PD, Auresenia JL (2009) Biological nitrogen and COD removal of nutrient-rich wastewater using aerobic and anaerobic reactor. Journal Water Resource and Protection 1: 376-380. 
Mwabi JK, Mamba BB, Momba MN (2012) Removal of Escherichia coli and faecal coliforms from surface water and groundwater by household water treatment devices/systems: a sustainable solution for improving water quality in rural community region. International Journal of Environmental Research and Public Health 9: 139-170.

O'Dell JW (1993) The determination of chemical oxygen demand by semi-automated colorimetry. US. Environmental Protection Agency. Cincinati, USA. https://www.epa.gov/sites/production/files/201508/documents/method_410-4_1993.pdf. Fecha de consulta 3 de mayo de 2015.

Oliveira SC, Von Sperling M (2011) Performance evaluation of different wastewater treatment technologies operating in a developing country. Journal of water, sanitation and hygiene for development 1: 37-56.

Olutiola PO, Awojobi KO, Oyedeji O, Ayansina AD, Cole OO (2010) Relationship between bacterial density and chemical composition of a tropical sewage oxidation pond. African Journal of Environmental Science and Technology 4: 595-602.

Panigatti MC, Boglione C, Griffa C, Boidi M, Schierano MC (2013) Tratamiento de efluentes cloacales utilizando cámara séptica y zanja filtrante. Revista AIDIS de Ingeniería y Ciencias Ambientales 6: 62-72.

SEMARNAP (2003a) Norma oficial mexicana NOM-001-SEMARNAT-1996. Que establece los límites máximos permisibles de contaminantes en las descargas de aguas residuales en aguas y bienes nacionales. Distrito Federal, México. 35p. http://biblioteca.semarnat.gob.mx/janium/Documentos/Ciga/agenda/D OFsr/DO2470.pdf. Fecha de consulta 23 de septiembre de 2015.

SEMARNAP (2003b) Norma oficial mexicana NOM-003-SEMARNAT-1997. Que establece los límites máximos permisibles de contaminantes para las aguas residuales tratadas que se reusen en servicios al público. Distrito Federal, México. 17 p. http://biblioteca.semarnat.gob.mx/janium/Documentos/Ciga/agenda/ PPD02/DO114OK.pdf. Fecha de consulta 22 de septiembre de 2015.

Suhendrayatna, Marwan, Andriani R, Fajriana Y, Elvitriana (2012) Removal of municipal wastewater BOD, COD, and TSS by phyto-reduction: A laboratory-scale comparison of aquatic plants at different species Typha latifolia and Saccharum spontaneum. International Journal of Engineering and Innovative Technology 2: 333-337.

Syamimi-Musa N, Azlina-Ahmad W (2010) Chemical oxygen demand reduction in industrial wastewater using locally isolated bacteria. Malaysian Journal of Fundamental and Applied Sciences 6: 88-92.

Tchobanoglous G, Burton FL, Stensel HD (2003) Wastewater Engineering Treatment and Reuse. 4th Edition. McGraw-Hill. Metcalf \& Eddy, Inc. New York, USA. 1819p.

Torkzaban S, Tazehkand SS, Walker SL, Bradford SA (2008) Transport and fate of bacteria in porous media: coupled effects of chemical conditions and space geometry. Water Resources Research 44: 1-12.

Toscano A, Langergraber G, Consoli S, Cirelli GL (2009) Modelling pollutant removal in a pilot-scale twostage subsurface flow constructed wetlands. Ecological Engineering 35: 281-289.

Vítěz T, Ševčíková J, Oppeltová P (2012) Evaluation of the effciency of selected wastewater treatment plant. Acta Universitatis Agriculturae et Silviculturae Mendelianae Brunensis 40: 173-180.

Vymazal J (2011) Constructed wetlands for wastewater treatment: five decades of experience. Environment Science and Technology 45: 61-69.

Wand H, Vacca G, Kuschk P, Krüger M, Kästner M (2007) Removal of bacteria by filtration in planted and non-planted sand columns. Water Research 41: 159-167. 
Windward GP, Avery LM, Frazer-Williams R, Pidou M, Jeffrey P, Stephenson T (2008) A study of the microbial quality of grey water and an evaluation of treatment technologies for reuse. Ecological Engineering 32: 187-197.

Zahraeifard V, Deng Z (2011) Hydraulic residence time computation for constructed wetland design. Ecological Engineering 37: 2087-2091. 
